\title{
Cellular Adaptation of the Rat Small Intestine after Proximal Enterectomy: Changes in Microvillous Enzymes and in the Secretory Component of Immunoglobulins
}

\author{
JEAN-PAUL BUTS, NADINE DE KEYSER, AND CHARLES DIVE
}

Laboratory of Gastroenterology, Faculty of Medicine, University of Louvain, Louvain, Belgium

\begin{abstract}
To investigate the adaptation of functions expressed by the villous and crypt cell of the intestinal mucosa after intestinal resection, a $\mathbf{5 0 \%}$ proximal enterectomy or a single transection was performed in 16 growing rats weighing 175-200 g. Ten days following the enterectomy, we determined the mucosal mass parameters (weight, protein, and DNA content), the activity of microvillous enzymes (lactase, sucrase, and aminopeptidase) in villus cells, and the concentration of the secretory component of immunoglobulins in crypt cells isolated from the proximal intestinal remnant. Mucosal hyperplasia was attested by the finding that mucosal weight, protein, and DNA content per $\mathrm{cm}$ of intestinal length were significantly $(p<0.01)$ higher $(+29$ to $+48 \%)$ in the resected group than in transected controls. The specific activity of lactase, sucrase, and aminopeptidase were significantly $(p<0.05)$ lower $(-23$ to $-56 \%)$ in villous cells isolated from the intestinal remnant of resected rats compared to controls. Sucrase activity was depressed in each cell fraction of the entire villous-crypt unit resulting in a lower villous to crypt gradient of enzyme activity. $K_{m}$ for the enzyme determined in villous cells was similar in both groups but the $V_{\max }$ was reduced proportionally to the enzyme activity in the resected group indicating less enzyme per cell. By contrast, the concentration of secretory component measured by an immunoradiometric assay in both villous and crypt cells was significantly $(p<0.05)$ increased $(+37$ to $45 \%)$ following proximal enterectomy. Our data indicate that the response of the epithelial cell to intestinal resection varies according to the metabolic function and that the mechanism of adaptation at the cellular level is complex. (Pediatr Res 22: 29-33, 1987)
\end{abstract}

Abbreviations

SC, secretory component

PBS, phosphate-buffered saline

IRMA, immunoradiometric assay

After extensive small bowel resection in the rat, profound structural, kinetic, and functional changes occur in the remaining intestine, allowing the animal to adapt to the shortened intestine (1). The morphological changes are dominated by villous hyperplasia including increased villous height and crypt depth and by

Received September 19, 1986; accepted February 2. 1987.

Reprint requests Jcan-Paul Buts, M.D., Departement de Pédiatrie, Cliniques Saint-Luc, 10 av. Hippocrate. 1200 Bruxelles. Belgium. dilatation and lengthening of the intestinal remnant $(2,4)$. The increase in mucosal mass reaches a peak 7 to 12 days after intestinal tissue loss (5). Concerning the available functional data, in vivo perfusion techniques in animals with proximal enterectomy show increased intestinal uptake of water, glucose, and amino acids by the remnant of the intestine $(2,6)$. These findings are contradicted by the observed reduction in uptake of sugars and amino acids by the same tissue in vitro (7). While the enhanced absorption of glucose and water in rat ileum after jejunectomy correlates closely with adaptive increments in villous height (2), most studies show unchanged rates of absorption as expressed in terms of mucosal weight or protein content rather than per unit length of small bowel (7).

Ultrastructural studies of intestinal epithelium after resection have yielded conflicting reports that microvilli are variously shorter (8), longer (9), or of normal dimensions (10). Similarily, conflicting studies have reported that cellular or tissue levels of microvillous enzymes such as disaccharidases are reduced $(7,11)$ or unchanged (12). The first objective of the present study was to determine the effect of proximal enterectomy on the activity of microvillous enzymes such as sucrase, lactase, and aminopeptidase measured in isolated epithelial cells. We also examined the distribution of sucrase along the villous-crypt unit in resected rats and transected controls. Several studies $(11,13)$ have demonstrated that proximal enterectomy in rats affects epithelial kinetics by increasing cell proliferation rate in the crypt compartment of the remaining intestine. The accelerated cell production is reflected by the greater activity of the pentose phosphate pathway and of the enzymes involved in pyrimidine synthesis (14). However, it is not established whether the increase in cell proliferation is associated with functional changes of the crypt cell itself. Therefore, the second objective of our study was to assess whether proximal enterectomy in the rat may influence the production of the SC of immunoglobulins, a glycoprotein mainly synthesized by the crypt cell (15).

\section{METHODS}

Animals and diet. Resection of $50 \%$ of the proximal small intestine or transection was performed on 16 young male Wistar rats weighing 175-200 g. Before surgery, rats were housed individually in polystyrene cages and provided with pellets (diet 103, UAR, Villemoisson-sur-Orge, France) and water ad libitum. Animal quarters were air-conditioned $\left(21 \pm 1^{\circ} \mathrm{C}\right)$ and had a 12 $\mathrm{h}$ light-dark cycle with lights on at $0730 \mathrm{~h}$.

Operations. The procedure of proximal enterectomy has been described in detail elsewhere (16). Briefly, after anesthesia with sodium pentobarbital (Nembutal, Abbott Laboratories, Belgium), the small intestine was exteriorized through a small midline incision and measured. Starting at $10 \mathrm{~cm}$ from the ligament 
of Treitz, $50 \%$ was excised. Stumps were reconnected end-toend and carefully replaced into the abdominal cavity. Following surgery, the rats were fed a standard chow diet ad libitum (diet 103, UAR).

Preparation of tissues. After 10 days, the animals were killed by decapitation and bled. The small intestine from the pylorus to the ileocecal valve was removed and flushed with ice cold isotonic saline. The total length was measured under constant fixed tension $(5 \mathrm{~g})$ and divided into three segments. Segment A was defined by the distance from the pylorus to the anastomosis (point of resection). The intestinal length from the anastomosis to the ileocaecal valve was divided into two equal segments $B$ and $\mathrm{C}$. Each segment was promptly opened lengthwise cleaned with wet filter paper and sponged between damp gauze. The mucosa was scraped with glass slides and weighed. It was thereafter wrapped in parafilm and stored at $-170^{\circ} \mathrm{C}$ until use.

To collect epithelial cells from villous tip to the crypt base, we used the Weiser's procedure (17) modified by Raul et al. (18). Briefly, rat jejunal segments (10 cm distant from the pylorus) were removed, everted, and submitted to successive incubations of $10 \mathrm{~min}$ at $37^{\circ} \mathrm{C}$ in PBS $(\mathrm{pH}=7.4)$ containing $1.5 \mathrm{mM}$ EDTA and $0.5 \mathrm{mM}$ dithiothreitol $\left(\right.$ no $\mathrm{Ca}^{2+}$ or $\mathrm{Mg}^{2+}$ ) under agitation at $170 \mathrm{rpm}$ in a waterbath shaker. By successive incubations, sequential fractions of isolated epithelial cells were obtained. The released cells were collected as described (19) and washed twice. Villous and crypt cell fractions were pooled (villous cells: fractions 1 to 5, crypt cells: fractions 5 to 10 ) and stored at $-20^{\circ} \mathrm{C}$ until use.

Analytic methods. The concentration of total secretory component (SC free and bound to immunoglobulins) was measured in rat jejunal villous and crypt cells by a double-antibody IRMA. The techniques for preparation and labeling of the IgG fraction of the anti-SC goat antiserum have been reported in detail elsewhere (20). The goat anti-SC rat antiserum was kindly provided by Dr. J. P. Vaerman (ICP, Brussels, Belgium). The successive steps of the IRMA have been described previously (20). A standard reference curve was made with purified $11 \mathrm{~s} \mathrm{IgA}$ at the following concentrations in $20 \%$ horse serum: $0,12.5,25$, $50,100,200,300$, and $400 \mathrm{ng} / \mathrm{ml}$ (measured by optical density at $280 \mathrm{~nm}$, using E1\% $\left.\%_{280}, 1 \mathrm{~cm}=13.8\right)$. The IRMA measured all forms of SC (free and bound to immunoglobulins) and results were calculated as equivalents of $11 \mathrm{~s}$ IgA concentration, which was the standard used. The limit of sensitivity of the assay $(+4$ $\mathrm{SD}$ above the radioactivity of the zero standard) was $4 \mathrm{ng} / \mathrm{ml}$. The final SC concentration in jejunal cells was expressed in $\mathrm{ng} /$ $\mathrm{mg}$ of protein.

Sucrase and lactase were assayed by the method of Messer and Dahlqvist (21). Activities were expressed as $\mu \mathrm{mol}$ of substrate hydrolyzed per min and per $g$ protein. Aminopeptidase was determined by the method of Maroux et al. (22) using L-alanine$p$-nitroanilide as substrate. One unit equals $1 \mu \mathrm{mol}$ of $p$-nitroan- ilide formed per min and per $g$ protein. Protein content in mucosa and in isolated cells was determined by the method of Lowry et al. (23). DNA was extracted by serial precipitations in cold perchloric acid and measured by the method of Burton (24) with modifications according to Giles and Myers (25). Polymerized calf thymus DNA (Sigma, St. Louis, MO) was used as standard. DNA was expressed in $\mathrm{mg} / \mathrm{g}$ of mucosa.

Calculations and statistical methods. Mucosal mass parameters (weight, DNA, protein) SC and enzyme activities were also calculated per $\mathrm{cm}$ of gut, removing the possibility of an artifact when data are related solely to protein. Differences between means were tested for statistical significance $(p<0.05)$ using a two-tailed Student's $t$ test.

\section{RESULTS}

Mortality after intestinal resection of transection was less than $10 \%$. After 10 days of feeding, all the animals of both groups appeared healthy and had gained weight. Table 1 shows animals and intestinal data for control and resected rats 10 days after entry into the study. The mean weight gain was similar in resected rats and transected controls (gain: +10 and $+14 \mathrm{~g}$, respectively). In the resected group, the remaining intestine appeared morphologically increased in both thickness and diameter. In each segment (A, B, C) of the small bowel, the values of intestinal and mucosal weight, mucosal protein, and DNA per $\mathrm{cm}$ of gut length were significantly increased in the resected group compared to the controls (Table 1). The increases in the mucosal mass parameters ranged between +29 and $+48 \%$.

Changes in the specific enzyme activity (units per mg of protein) for lactase, sucrase, and aminopeptidase are depicted in Figure 1. Compared to transected controls, the enzyme activities were all significantly $(p<0.05)$ reduced (sucrase $-41 \%$, lactase $-56 \%$, aminopeptidase $-23 \%$ versus controls) in villous epithelial cells collected from the proximal intestinal remnant (segment $A$, Fig. 1). There was no difference in the sucrase to lactase ratio between the two groups (resected group: S/L: $15.6 \pm 1.8$, transected group: $13.1 \pm 1.5$ ). To document whether intestinal resection could influence the enzyme distribution along the villouscrypt unit, we measured sucrase activity in successive cell fractions collected from the villous tip to the crypt base. The results are illustrated in Figure 2 for both resected animals (Fig. $2 A$ ) and transected controls (Fig. $2 B$ ). In resected animals, the enzyme activity was decreased in villous and crypt cells whatever the position of the cell in the villous-crypt unit. The resulting villous to crypt gradient of enzyme activity also was lower in resected animals than in transected controls. On the other hand, $\mathrm{K}_{\mathrm{m}}$ for sucrase determined in isolated villous cells was similar in both groups [transections mean $\pm \mathrm{SE}: 18.5 \pm 0.8$ versus resections: $17.7 \pm 0.8(\mathrm{mM})$ of substrate] but the $\mathrm{V}_{\max }$ was significantly $(p$ $<0.05$ ) reduced in the resected group $(-35 \%)$ (transections mean

Table 1.

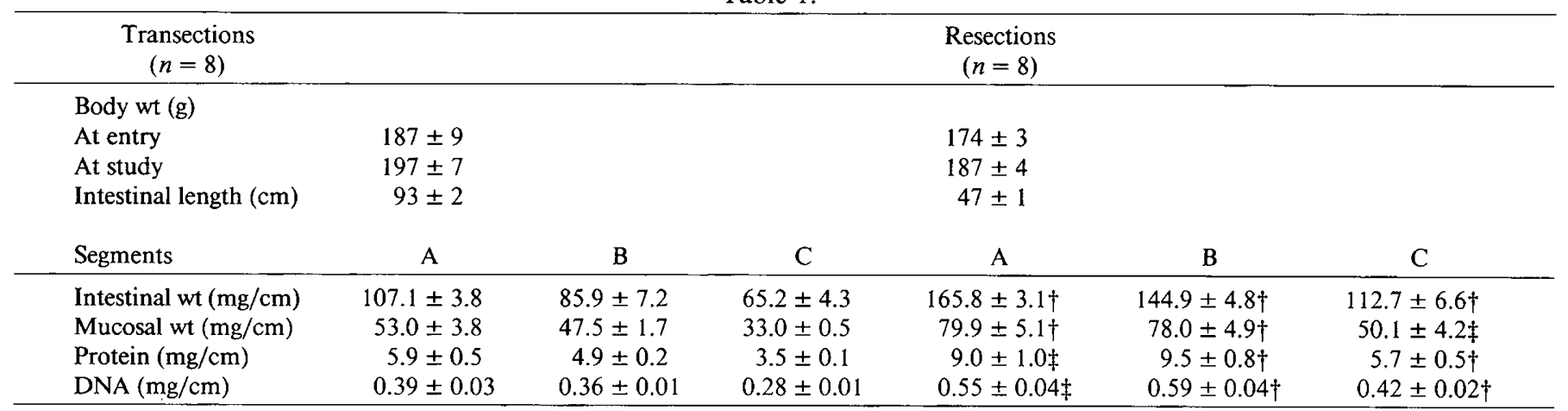

$*$ Values are mean $\pm \mathrm{SE}$.

$\dagger p<0.001$ versus controls transected.

$\ddagger p<0.01$. 
SUCRASE

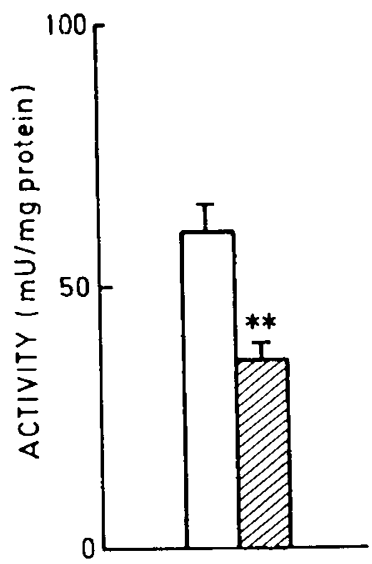

AMINOPEPTIDASE

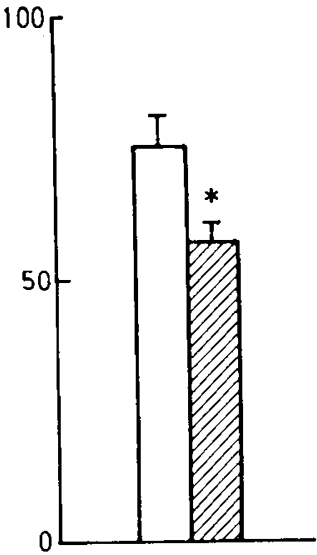

LACTASE

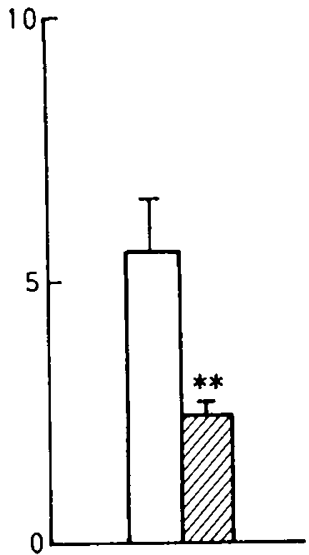

TRANSECTIONS (8)

RESECTIONS (8)

Fig. 1. Changes in the specific activity of microvillous enzymes measured in isolated villus cells from intestinal remnants of resected rats and transected controls. Values are mean $\pm \mathrm{SE} .{ }^{*} p<0.05 ;{ }^{* *} p<0.01$ versus controls.
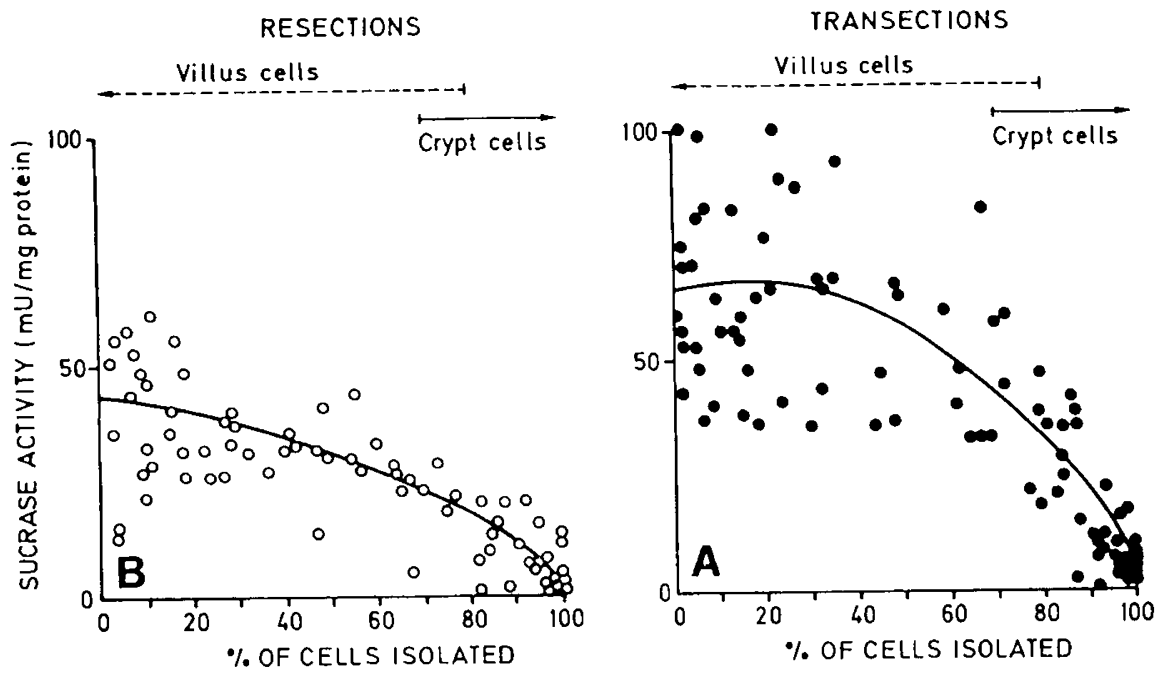

Fig. 2. Distribution of sucrase activity along the villus crypt unit in resected rats (Fig. $2 A$ ) and transected controls (Fig. $2 B$ ). The $100 \%$ of cells isolated correspond to the sum of the fractions expressed as protein. The percentage of cells isolated in each successive fraction was determined by the proportion of cell protein isolated in a given fraction. The mean curve for the enzyme activities measured in different cell fractions was obtained by a polynomal multiple regression analysis (second degree). The villous to crypt gradient of enzyme activity is lower in resected animals than in transected controls.

mean $\pm \mathrm{SE}: 171 \pm 20.1$ versus resections: $111 \pm 7.4 \mathrm{U} \cdot \mathrm{g}$. protein $^{-1}$ ) proportionally to the enzyme activity $(-41 \%)$. This indicates that there was less amount of enzyme rather than enzyme inactivation. The changes in SC concentration are shown in Figure 3.

In villous and crypt cells isolated from the proximal intestinal remnant, the concentration of SC (expressed per mg of protein) was significantly $(p<0.05)$ increased, respectively, by +37 and $+44 \%$ over the mean concentrations obtained for the controls. Similarly, SC concentration, when expressed per $\mathrm{cm}$ of intestinal length was also increased $(p<0.01)$ in segment $A(+33 \%$ versus controls) and in segment $\mathrm{B}(+45 \%$ versus controls $)$ after proximal enterectomy.

\section{DISCUSSION}

Previous studies in mammals have shown that following small bowel resection, the remaining intestine undergoes an increase in mucosal mass with enlargement of intestinal villi $(1,3,16)$. This compensatory response is more marked in the ileum than in the jejunum $(1,2)$, develops rapidly within $48 \mathrm{~h}(5)$, and persists for several months at least $(26)$. Several reports $(5,27)$ have demonstrated that mucosal hyperplasia and the morphological changes are maximal 12 days after a $70 \%$ proximal enterectomy. For this reason, we chose a period of 10 days after proximal enterectomy to conduct our studies. A $50 \%$ proximal resection was performed since it has been documented that the maximal increase in villous height is attained after a resection of $45 \%$ of the initial intestinal length and that after more extensive resection no further increment occurs (27).

Table 1 shows clearly that 10 days after $50 \%$ proximal enterectomy, the mucosal mass parameters (weight, protein, and DNA) were increased (from +29 to $+48 \%$ ) compared to the control values. However, microvillous enzyme activities for lactase, sucrase, and aminopeptidase were significantly reduced in villous cells collected from the proximal intestinal remnant. In 

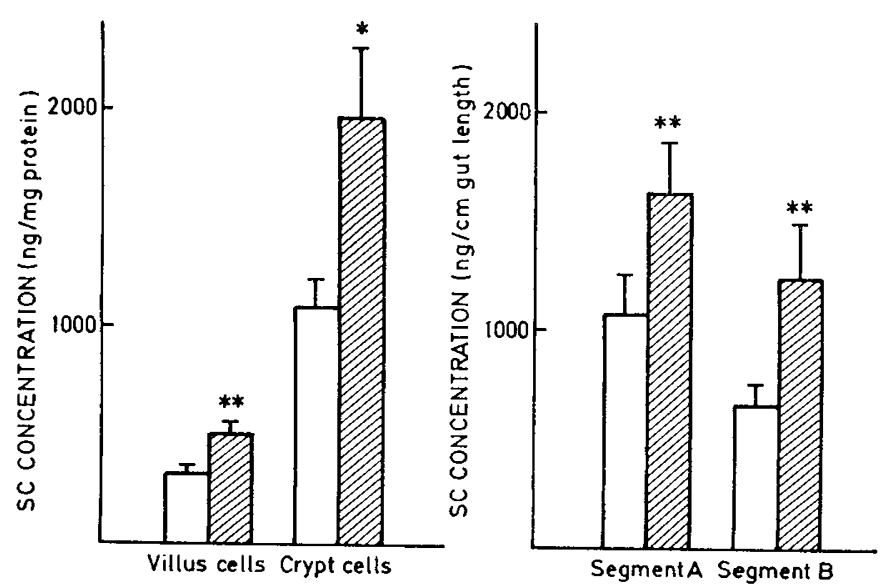

TRANSECTIONS ( 8 )

RESECTIONS (8)

Fig. 3. Changes in SC concentration in villous and crypt cells isolated from the proximal intestinal remnant and in segments $A$ and $B$ after proximal enterectomy or single transection. Values are mean $\pm \mathrm{SE} .^{*} p$ $<0.05$ versus controls; ${ }^{* *} p<0.01$ versus controls.

addition, from the data shown in Figure 2, it appears that sucrase activity was decreased in each cell fraction over the entire villouscrypt unit. The $\mathrm{K}_{\mathrm{m}}$ for the enzyme remained similar in resected and control groups whereas the $V_{\max }$ in the resected group was significantly reduced, proportionally to the enzyme activity indicating less amount of enzyme per cell rather than enzyme inactivation. A similar decrease in disaccharidase activity has been observed by others (11) in mucosal homogenates and in epithelial cells isolated from intestinal remnants.

The decrease in microvillous enzymes that occurs over the entire villus crypt unit is consistent with a younger population of immature cells. Indeed, some evidence supports the concept that after resection the intestinal mucosa acquires characteristics of metabolic immaturity. Whereas normal rats depend on energy supplied by oxidative phosphorylation in order to transport vitamin $A$, resected animals utilize the energy supplied by anaerobic glycolytic phosphorylation (28). Similarly, Weiser and Hernandez (7) found that when glucose transport was measured in everted gut sacs as a function of weight of the segment, there was a decrease in capacity of glucose transport in segments from distally resected animals. These alterations in cell metabolism concur with our findings on microvillous enzymes and are characteristic of fetal tissue and rapidly dividing immature cells. Although the epithelial cells are immature after resection with decrease of some of their metabolic functions, no change has been observed in their ultrastructure especially of the microvilli (29).

Proximal enterectomy in rats affects epithelial kinetics by increasing cell proliferation rate in the crypt compartment. In the crypts, the accelerated cell production is associated with a greater activity of the pentose phosphate pathway and of enzymes involved in pyrimidine synthesis (14). However, it is not established whether the increase in crypt cell proliferation is associated with metabolic changes of the crypt cell itself. Therefore, we measured the concentration of SC, a glycoprotein mainly produced by the crypt cells (19). SC was chosen for this experiment because as are disaccharidases, it is a surface membrane glycoprotein synthesized by the crypt cell and translocated after migration via the basolateral membrane to the apical membrane of the epithelial cell (30). At the basolateral membrane, SC acts as a receptor for dimeric $\operatorname{IgA}(31)$ and is released into endoluminal secretions by enzymatic cleavage $(30,31)$. Our data indicate that the concentration of SC expressed both per unit of protein and per intestinal segment increased significantly after intestinal re- section. In contrast to the decrease in microvillous enzyme activity, the concentration of SC was also increased in epithelial cells isolated from the upper part of the villi. The reason why certain metabolic functions of the villous cells such as the activity of brush border hydrolases and the capacity of nutrient transport are depressed while other functions such as the production of SC are enhanced after enterectomy is unknown but it suggests that in the intestinal remnant, the mechanism of adaptation at the cellular level is complex.

In young infants with short bowel syndrome, especially when the ileocecal valve has been resected, bacterial overgrowth and pathogen infection of the remaining gut leading to episodes of bacteriemia and sepsis may be lethal complications (32). The present findings of an enhanced production of total SC (free and bound to immunoglobulins) by the crypt cells after enterectomy may have important clinical relevance on the capacities of the local immune defenses of the host. Indeed, SC-IgA appears to be at the first line of immune defenses of the gastrointestinal tract by binding specifically to external pathogens and toxins $(33,34)$. Further studies will determine to what extent the increased production of SC-IgA by the remaining intestine after enterectomy plays a specific protective role against pathogen infection.

Ackowledgments. The authors thank Lucien Erculisse for expert technical assistance and Dominique Vermeulen for preparation of the manuscript.

\section{REFERENCES}

1. Williamson RCN 1978 Intestinal adaptation: structural, functional and cytokinetic changes. N Engl J Med 298:1393-1399

2. Dowling RH, Booth CC 1967 Structural and functional changes following small intestinal resection in the rat. Clin Sci 32:139-149

3. Nygaard K 1967 Resection of the small intestine in rats III. Morphological changes in the intestinal tract. Acta Chir Scand 133:233-248

4. Wilmore DW, Dudrick SJ, Daly JM 1971 The role of nutrition in the adaptation of the small intestine after massive resection. Surg Gynecol Obstet 132:673-680

5. Hanson WR, Osborne JW, Sharp JG 1977 Compensation by the residual intestine after intestine resection in the rat II. Influence of postoperative time interval. Gastroenterology 72:701-705

6. Bury KD 1972 Carbohydrate digestion and absorption after massive resection of the small intestine. Surg Gynecol Obstet 135:177-187

7. Weser E, Hernandez BA 1971 Studies of small bowel adaptation after intestinal resection in the rat. Gastroenterology 60:69-75

8. Genyk SN 1971 Ultrastructure of the apical part of the epithelial cells of the mucous membrane of the small intestine after extensive experimental enterectomy. Bull Exp Biol Med 72:964-967

9. Tilson MD, Wright HK 1971 The effect of resection of the small intestine upon the fine structure of the intestinal epithelium. Surg Gynecol Obstet 134:992-994

10. Grönqvist B, Engström B, Grimelins L 1975 Morphological studies of the rat small intestine after jejuno-ileal transposition. Acta Chir Scand 141:208-217

11. McCarthy DM, Kimn SY 1973 Changes in sucrase, enterokinase and peptide hydrolase after intestinal resection. J Clin Invest 52:942-951

12. Bury KD 1971 Disaccharidase activity and carbohydrate absorption after intestinal resection. Surg Forum 22:367

13. McDermott FT, Roudnew B 1976 lleal crypt cell population kinetics after 40 per cent small bowel resection: autoradiographic studies in the rat. Gastroenterology 70:707-711

14. Nakayama H, Weser E 1972 Adaptation of small bowel after intestinal resection: increase in the pentose phosphate pathway. Biochim Biophys Acta 279:416-423

15. Mostov KE, Blobel G 1982 A transmembrane precursor of secretory component. The receptor for transcellular transport of polymeric immunoglobulins. J Biol Chem 257:11816-11821

16. Buts JP, Morin CL, Ling V 1979 Influence of dietary components on intestinal adaptation after small bowel resection in rats. Clin Invest Med 2:59-66

17. Weiser MM 1973 Intestinal epithelial cell surface membrane glycoprotein synthesis. J Biol Chem 248:2536-2541

18. Raul F, Simon P, Kedinger M, Haffen K 1977 Intestinal enzyme activities in isolated villus and crypt cells during postnatal development of the rat. Cell Tissue Res 176:167-178

19. Buts JP, Delacroix DL 1985 Ontogenic changes in secretory component expression by villus and crypt cells of rat small intestine. Immunology 54:181-187

20. Delacroix DL, Vaerman JP 1981 A solid-phase direct competition radioimmunoassay for quantitation of secretory IgA in human serum. J Immunol Methods 40:345-358

21. Messer M, Dahlquist A 1966 A one step ultramicromethod for the assay of 
intestinal disaccharidases. Anal Biochim 14:376-392

22. Maroux S, Louvard D, Baratti J 1973 The aminopeptidase from the hog intestinal brush border. Biochim Biophys Acta 321:282-295

23. Lowry OH, Rosebrough NJ, Farr AL, Randall RJJ 1951 Protein measuremen with the folin reagent. J Biol Chem 193:265-275

24. Burton K 1956 A study of the conditions and mechanism of the diphenylamine reaction for the colorimetric estimation of deoxyribonucleic acid. Biochim J $62: 315-323$

25. Giles KW, Meyers M 1965 An improved diphenylamine method for the estimation of DNA. Nature 206:93-94

26. Weser E, Tawil T 1976 Epithelial cell loss in remaining intestine after small bowel resection in the rat. Gastroenterology 71:412-415

27. Menge H, Robinson JWL 1978 The relationship between the functional and structural alterations in the rat small intestine following proximal resection of varying extents. Res Exp Med (Berl) 173:41-53

28. Loran MR, Althausen TL 1959 Transport of vitamin A in vitro across normal isolated rat intestine and intestine subject to "partial" resection. Am J Physiol 197:1333-1336

29. Skala MD, Konradava V 1969 Hypertrophy of the small intestine after its partial resection in the rat: ultrastructure of the intestinal epithelium. Am J Dig Dis 14:182-188

30. Brandtzaeg P 1981 Transport models for secretory IgA and secretory IgM. Clin Exp Immunol 44:221-232

31. Kühn LC, Kraehenbuhl JP 1979 Role of secretory component, a secreted glycoprotein in the specific uptake of IgA dimer by epithelial cells. J Biol Chem 254:1172-1181

32. Cannon RA, Byrne WJ, Ament ME, Gates B, O'Connor M, Fonkalsrud EW 1980 Home parenteral nutrition in infants. J Pediatr 96:1098-1104

33. Williams RC, Gibbons RJ 1972 Inhibition of bacterial adherence by secretory immunoglobulin A: a mechanism of antigen disposal. Science 177:697-699

34. Stokes GR, Soothill JF, Turner MW 1975 Immune exclusion is a function of IgA. Nature 255:745-746 